OPEN ACCESS

Edited by:

Rosalba Lanciotti,

Università degli Studi di Bologna, Italy

Reviewed by:

Panagiotis Skandamis,

Agricultural University of Athens,

Greece

Antonio Bevilacqua,

University of Foggia, Italy

*Correspondence:

Ramakrishna Nannapaneni

nannapaneni@fsnhp.msstate.edu

Specialty section:

This article was submitted to

Food Microbiology,

a section of the journal

Frontiers in Microbiology

Received: 26 January 2018 Accepted: 13 August 2018

Published: 31 August 2018

Citation:

Bansal M, Nannapaneni R,

Sharma CS and Kiess A (2018)

Listeria monocytogenes Response

to Sublethal Chlorine Induced

Oxidative Stress on Homologous and Heterologous Stress Adaptation.

Front. Microbiol. 9:2050.

doi: 10.3389/fmicb.2018.02050

\section{Listeria monocytogenes Response to Sublethal Chlorine Induced Oxidative Stress on Homologous and Heterologous Stress Adaptation}

\author{
Mohit Bansal' ${ }^{1}$, Ramakrishna Nannapaneni ${ }^{2 *}$, Chander S. Sharma ${ }^{1}$ and Aaron Kiess ${ }^{1}$ \\ ${ }^{1}$ Department of Poultry Science, Mississippi State University, Starkville, MS, United States, ${ }^{2}$ Department of Food Science, \\ Nutrition and Health Promotion, Mississippi State University, Starkville, MS, United States
}

The objective of this study was to determine the effect of chlorine induced sublethal oxidative stress against homologous and heterologous stress adaptations in five Listeria monocytogenes $(\mathrm{Lm})$ strains. Lm cells were exposed to gradually increasing sublethal concentrations of total chlorine/day: 250 ppm (day 1), 270 ppm (day 2), 290 ppm (day 3), 310 ppm (day 4), 330 ppm (day 5), 350 ppm (day 6), and 375 ppm (day 7) in tryptic soy broth (TSB). Changes in minimum inhibitory concentration (MIC) and minimum bactericidal concentration (MBC) of $L m$ cells exposed to chlorine and control (non-adapted cells) were determined by the macro-dilution method. Chlorine-adapted Lm cells were also evaluated for changes in antibiotic resistance using the KirbyBauer disk diffusion and MIC double dilution assay as per the Clinical and Laboratory Standards Institute (CLSI, 2016) guidelines. In four Lm strains (Scott A, V7, FSL-N1227 and FSL-F6-154) after adapted to sublethal chlorine, the MIC (600 ppm) and MBC (700 ppm) values of chlorine were slightly higher as compared to control (500 ppm $\mathrm{MIC}$, and 600 ppm MBC). The Kirby-Bauer and MIC double dilution assays showed some significant changes in antibiotic susceptibility patterns for antibiotics such as streptomycin, gentamicin and ceftriaxone $(p<0.05)$. However, the changes in zones of inhibition and MIC values to all antibiotics tested for the chlorine-adapted and non-adapted (control) Lm cells were still within the susceptible range. Transmission electron microscopy studies showed that changes in cell wall and membrane integrity resulting, from the elongation of cells, may contribute to the possible routes of its increase in tolerance to chlorine and selective antibiotics. These findings indicate that the continuous exposure of $L m$ cells to chlorine may lead to significant changes in homologs and heterologous stress adaptation.

Keywords: Listeria monocytogenes, sublethal oxidative stress, chlorine, sodium hypochlorite, stress adaptation

\section{INTRODUCTION}

Listeria monocytogenes is a ubiquitous Gram-positive foodborne bacterial pathogen. Listeriosis, caused by Listeria monocytogenes, is a fatal foodborne disease with a high hospitalization rate (>90\%), and commonly causes an infection in susceptible populations which include immunocompromised individuals and pregnant women (Scallan et al., 2011). Though listeriosis 
has a low incidence rate $(<3 \%)$ in the healthy population, it is the leading cause of foodborne related deaths and causes 250 deaths annually in the United States (Mead et al., 1999; CDC, 2012). This foodborne pathogen causes severe nervous symptoms such as meningitis, meningoencephalitis (invasive listeriosis) and febrile gastroenteritis (non-invasive listeriosis) in the susceptible population (Allerberger and Wagner, 2010). Often, non-invasive listeriosis the cases are commonly treated with antibiotics such as ampicillin, amoxicillin, gentamicin, or cephalosporin. However, a few strains of L. monocytogenes have been found to have intrinsic resistance against third generation cephalosporin drugs (Kose and Yakupogullari, 2015).

In the food-processing environments, L. monocytogenes is commonly exposed to oxidative stress produced by sanitizers and disinfectants or antimicrobial rinses like chlorine (Gao and Liu, 2014; Gray et al., 2014). In the food-production environments, indiscriminate and over usage of antibiotics has raised concerns over the emergence of antibiotic resistance (Fair and Tor, 2014). Since the 1960s, there has been a gradual increase in the number of antibiotic resistant cases from all over the world with treatment costs exceeding \$20 billion dollars annually (Fair and Tor, 2014). Other published findings show that continuous exposure of bacteria to disinfectants does not inhibit the complete metabolic and/or genetic activity of bacteria and may induce the phenotypic resistance mechanism which is expressed in the form of changes in cell wall and membrane structures (Wiuff et al., 2005; McMahon et al., 2007) or altered activity of specific or non-specific efflux pumps (Levin and Rozen, 2006).

Biocides are commonly used for routine cleaning, sanitation and disinfection in the food industry and hospitals (Holah et al., 2002; Seier-Petersen, 2013). Biocide's lethal concentration might reduce to sublethal concentration in food processing plant especially in places where water and organic matter are abundant (Carpentier and Cerf, 2011). Continuous exposure to sublethal concentrations of these biocides/antimicrobials while cleaning and sanitizing process may induce stress adaptation or response in food borne pathogens (Capozzi et al., 2009). Previous studies reported that the persistence of certain strain of L. monocytogenes in food processing environment is not a random phenomenon but directly related with different situation which results in sublethal conditions such as inefficient cleaning before disinfection, disinfection of wet surface or dosage failure (Martínez-Suárez et al., 2016). In response to sublethal biocide stress, bacteria can co-select genes responsible for encoding tolerance to both same or different biocides and antibiotics (Henshaw and O'Carroll, 2009). In a previous study, Romero et al. (2017) found significant correlation between occurrence of antibiotic and biocide resistance in bacterial isolates from seafood.

Phenotypic adaptations, a form of temporary or sustained antibiotic tolerance, in response to sublethal stresses include changes in the permeability of the cell membrane, and increased expression of specific or non-specific efflux pumps (Forbes et al., 2014). McMahon et al. (2007) found that exposure of low $\mathrm{pH}$ or high $\mathrm{NaCl}$ concentrations can trigger the development of antibiotic resitance in subpopulations of pathogens. Apart from other factors, bile acids also have the capacity to induce oxidative stress adaptation in L. monocytogenes. Increased expression of bile salt hydrolase by the bacterium in response to bile salt exposure can aid in L. monocytogenes survival (Begley et al., 2005). Later, Gadea et al. (2017) observed repeated exposure of bacteria to QAC biocide can co-select for antibiotic tolerance which could be temporary or sustained.

There is a lack of knowledge on the influence of continuously increasing doses of sublethal chlorine for short term exposure on L. monocytogenes homologous adaptation (tolerance to same biocide) and heterologous adaptation (cross-resistance to other biocides and antibiotics). Therefore, three objectives were addressed in this study: (i) to determine homologous stress adaptation to chlorine in L. monocytogenes strains by measuring the changes in minimum inhibitory concentration (MIC) and minimum bactericidal concentration (MBC); (ii) to determine the cross-resistance to commonly used antibiotics by measuring changes in zones of inhibition and MIC in L. monocytogenes cells after exposure to sublethal chlorine; (iii) to determine ultrastructural changes in L. monocytogenes after exposure to sublethal chlorine by transmission electron microscopy.

\section{MATERIALS AND METHODS}

\section{Bacterial Strains and Culture Preparation}

Five L. monocytogenes strains used in this study are listed in Table 1. All bacterial strains were stored as stock cultures in tryptic soy broth (TSB) supplemented with 25\% glycerol at $-80^{\circ} \mathrm{C}$. This bacteriological media, Difco (Becton Dickinson, Sparks, MD, United States) was used for all experiments in the present study. Prior to each experiment, individual bacterial strains were cultured in $10 \mathrm{ml}$ of TSB at $37^{\circ} \mathrm{C}$ for two consecutives $24 \mathrm{~h}$ cycles to remove any cold stress in working cultures. Following overnight incubation, the culture was centrifuged at $5000 \times g$ for $10 \mathrm{~min}$ at $4^{\circ} \mathrm{C}$ and the collected pellet resuspended in $10 \mathrm{ml}$ of TSB ( $\mathrm{pH} \mathrm{7.2)}$. Serial 10-fold dilutions were plated on duplicate tryptic soy agar (TSA) and modified oxford agar plates

TABLE 1 | List of Listeria monocytogenes strains and their sources used in this study.

\begin{tabular}{|c|c|c|c|c|}
\hline No. & L. monocytogenes strains & Lineage & Serovar & First reported outbreak \\
\hline (1) & L. monocytogenes FSL F6-154 & $\|$ & $1 / 2 a$ & Food, epidemic (sliced turkey) (2000) \\
\hline (2) & L. monocytogenes FSL N1-227 & 1 & $1 / 2 \mathrm{a}$ & Food, epidemic (US 1998-1999) \\
\hline (3) & L. monocytogenes ATCC 19116 & III & $4 c$ & Poultry, UW \\
\hline$(4)$ & L. monocytogenes Scott A & 1 & $4 b$ & Human epidemic (Mass, 1983) \\
\hline$(5)$ & L. monocytogenes $\vee 7$ & $\|$ & $1 / 2 \mathrm{a}$ & Raw milk, FDA \\
\hline
\end{tabular}


for enumeration and confirmation, respectively. The plates were analyzed for CFU after $24 \mathrm{~h}$ incubation at $37^{\circ} \mathrm{C}$.

\section{Sodium Hypochlorite}

A 5\% stock solution of Sodium hypochlorite (Acros Organics, New Jersey, United States) was used as the source of chlorine. The stock solution was used to prepare the working concentrations of chlorine in TSB. Prior to each experiment, total and free available chlorine was measured using an $\mathrm{HACH}$ (chlorine test kit) Pocket Colorimeter (HACH Company, Loveland, CO, United States).

\section{Minimum Inhibitory Concentration (MIC) and Minimum Bactericidal Concentration (MBC) Assay}

The MIC was determined by the macro-dilution method with minor modifications of the Clinical and Laboratory Standards Institute (CLSI, 2016). The overnight culture of $L$. monocytogenes at $10^{9} \mathrm{CFU} / \mathrm{ml}$ was diluted in TSB to obtain a final concentration of $10^{6} \mathrm{CFU} / \mathrm{ml}$ for the MIC assay. The total available chlorine concentration range of 200-800 ppm, with $100 \mathrm{ppm}$ increments, was prepared in $10 \mathrm{ml}$ volumes of TSB. An aliquot $(100 \mu \mathrm{L})$ of L. monocytogenes suspension $\left(10^{6} \mathrm{CFU} / \mathrm{ml}\right)$ was added to each tube containing working chlorine dilutions to observe bacterial growth by turbidity changes after incubation at $37^{\circ} \mathrm{C}$ for $24 \mathrm{~h}$. Tubes with L. monocytogenes inoculum without chlorine and tubes with TSB alone were used as a positive and negative control, respectively. MIC was determined to be the lowest concentration of available chlorine which inhibited the visible growth of L. monocytogenes after $24 \mathrm{~h}$ of incubation.

Aliquots of $100 \mu \mathrm{L}$ from tubes without visible growth of L. monocytogenes were spread plated onto duplicate TSA plates to determine the minimum bactericidal concentration (concentration of available chlorine that kills all L. monocytogenes cells after $24 \mathrm{~h}$ incubation at $37^{\circ} \mathrm{C}$ ).

\section{Chlorine Induced Oxidative Stress Adaptation in Listeria monocytogenes}

The objective of this study to evaluate the sublethal chlorine induced oxidative stress on homologous and heterologous tolerance in L. monocytogenes under laboratory condition that simulated to food processing plant. The approach was abusive disinfection, or cleaning procedure or abundance of water and organic matter in food processing environment may responsible for sublethal chlorine exposure to L. monocytogenes. A modified sublethal chlorine adaptation protocol for a short period of 7 days was used in the present study. An aliquot $(100 \mu \mathrm{L})$ of a $24 \mathrm{~h}$ previously prepared bacterial culture, was added to $10 \mathrm{ml}$ of TSB with the initial $250 \mathrm{ppm}$ chlorine concentration (day 1). Subsequently $100 \mu \mathrm{l}\left(\sim 10^{7} \mathrm{CFU} / \mathrm{ml}\right)$ of a previous day incubated culture $(250 \mathrm{ppm})$ after $24 \mathrm{~h}$ was transferred into fresh TSB with the gradually increasing chlorine concentrations of $20 \mathrm{ppm} /$ day, i.e., $270 \mathrm{ppm}$ (day 2), $290 \mathrm{ppm}$ (day 3), $310 \mathrm{ppm}$ (day 4), $330 \mathrm{ppm}$ (day 5), and $350 \mathrm{ppm}$ (day 6). Finally, on day 7, the final chlorine concentration of $375 \mathrm{ppm}$ in TSB was obtained by increasing $25 \mathrm{ppm}$ in previous day culture. Therefore, L. monocytogenes adapted cells from three different sublethal oxidative stress levels were obtained: (1) at $250 \mathrm{ppm}$ (1/2 MIC) for 1 day, (2) by gradual exposure from $250 \mathrm{ppm}$ (1/2 MIC) to $330 \mathrm{ppm}$ (2/3 MIC) over 5 days; and (3) by gradual exposure from $250 \mathrm{ppm}$ (1/2 MIC) to $375 \mathrm{ppm}$ (3/4 MIC) over 7 days. Control (non-adapted) cells were also passaged and harvested along with the adapted cells in similar fashion but in the absence of chlorine.

\section{Viable Cell Counts}

Sublethal chlorine adapted (250 ppm, 250-330 ppm, or 250$375 \mathrm{ppm}$ ) and control (non-adapted) were tested for turbidity at $\mathrm{OD}_{600}$ and $\mathrm{CFU}$ counts $/ \mathrm{ml}$ after their overnight incubation periods. $\mathrm{OD}_{600}$ of both adapted and non-adapted was evaluated with spectrophotometer (Model ELx800, BioTek Instruments, Winooski, VT, United States). CFU were enumerated from serial dilution of $100 \mu \mathrm{l}$ of overnight grown non-adapted and chlorine adapted treatments in $0.1 \%$ buffered peptone water, and aliquot of $100 \mu \mathrm{l}$ from each dilution was plated on duplicated TSA plate and modified oxford agar plates for incubation at $37^{\circ} \mathrm{C}$ for $48 \mathrm{~h}$.

\section{Determination of Chlorine Tolerance Development After Chlorine Adaptation}

The chlorine adaptive tolerance was measured by determining the MIC and MBC for the control and chlorine adapted cells using broth macro dilution method (CLSI, 2016). Initial inoculum size of $10^{6} \mathrm{CFU} / \mathrm{ml}$ of control and three sublethal oxidative stress levels (250 ppm, 250-330 ppm, or 250-375 ppm) cells was inoculated in $10 \mathrm{~mL}$ TSB with chlorine at concentrations $(500,600,700$, and $800 \mathrm{ppm})$ that were equivalent or above the MIC to measure chlorine adaptation in terms of MIC changes and incubated at $37^{\circ} \mathrm{C}$ for $24 \mathrm{~h}$. Tubes with no visible turbidity after incubation was considered as MIC. To assess changes in $\mathrm{MBC}$, an aliquot of $100 \mu \mathrm{l}$ from $24 \mathrm{~h}$ previously incubated chlorine containing TSB tubes was spread plated on duplicated TSA plate and incubated for $24 \mathrm{~h}$ at $37^{\circ} \mathrm{C}$. Complete inhibition of L. monocytogenes growth on TSA agar plate from lowest chlorine concentration containing TSB tube was considered as MBC.

\section{Determination of Antibiotic Susceptibility} Antibiotic MIC Determination by Disk-Diffusion Assay

The Kirby-Bauer disk-diffusion method was used to compare the zones of inhibition of L. monocytogenes oxidative stress adapted cells to their controls. Cells from controls and sublethal oxidative stress levels (after exposure to $250 \mathrm{ppm}$ for 1 day, 250-330 ppm over 5 days, and 250-375 ppm over 7 days) were obtained and pelleted after centrifugation at $5000 \times \mathrm{g}$ for $10 \mathrm{~min}$ at $4^{\circ} \mathrm{C}$. Cells were resuspended in $10 \mathrm{ml}$ of fresh TSB. Colonies were isolated on fresh TSA plates after incubation at $37^{\circ} \mathrm{C}$ for $24 \mathrm{~h}$. McFarland standards were prepared in $0.1 \%$ peptone water from colonies obtained from both the control and sublethal oxidative stress adapted cells. Aliquots were swabbed on Mueller-Hinton agar and antibiotic disks were placed on the plate. The plates were incubated at $37^{\circ} \mathrm{C}$ for $24 \mathrm{~h}$. The zones of inhibition (mm) for different antibiotics were obtained for L. monocytogenes cells exposed to three chlorine oxidative stress levels of $250 \mathrm{ppm}$ for 1 day, 250-330 ppm over 5 days, or 250-375 ppm over 7 days and control (non-adapted) cells. 
The antibiotic disks used were: amoxicillin/clavulanic acid (AMC, $30 \mu \mathrm{g}$ ), gentamicin (GEN, $10 \mu \mathrm{g}$ ), Sulfamethoxazole/trimethoprim (SXT, $25 \mu \mathrm{g}$ ), streptomycin (STR, $10 \mu \mathrm{g}$ ), nalidixic acid (NA, $30 \mu \mathrm{g}$ ), ciprofloxacin (CIP, $5 \mu \mathrm{g}$ ), ceftriaxone (CTX, $30 \mu \mathrm{g}$ ), ampicillin (AMP, $10 \mu \mathrm{g}$ ), vancomycin (VAN, $30 \mu \mathrm{g}$ ), and rifampicin (RIF, $5 \mu \mathrm{g}$ ). The zones of inhibition were measured according to the guidelines CLSI (2016).

\section{Antibiotic MIC Determination by Micro-Dilution Assay}

The stock solution of antibiotics was prepared as the manufactures recommended (Table 2). Working concentrations were obtained in Mueller-Hinton broth (MHB) from stock solutions. The MIC was determined by serial double fold dilutions for each antibiotic obtained in MHB using a 96-well round bottom sterile polystyrene microtiter plate (12 columns by 8 rows). Eight serial double dilutions were acquired in 8 columns and were duplicated in 4 rows. The MIC breakpoints recommended by the CLSI (2016) were used to observe the results as the lowest concentration of antibiotics which inhibited the visible growth as susceptible, intermediate or resistant. The susceptible range of each antibiotic is listed in Table 2. One well of MHB with L. monocytogenes inoculum and antibiotics was used as a positive control and one well with only MHB was used as the negative control. The lowest concentration of antibiotics that inhibited the button formation and yielded no turbidity was considered the MIC. The MIC values from all three sublethal chlorine oxidative stress levels (250 ppm for 1 day, 250-330 ppm over 5 days, or 250-375 ppm over 7 days) were obtained and compared to the control cells value.

\section{Determination of Ultrastructure Changes in the Chlorine Adapted Cells by Transmission Electron Microscopy}

Transmission electron microscopy (TEM) was used to investigate the ultrastructural changes in L. monocytogenes cells after sublethal chlorine exposure. As explained earlier, L. monocytogenes cells were exposed to gradually increasing concentrations of chlorine from $250 \mathrm{ppm}$ (day 1) to the final concentration of $375 \mathrm{ppm}$ (day 7) in TSB. L. monocytogenes strains, Scott A, V7 and FSL-N1-227 chlorine adapted cells were harvested after exposure to a final 375 ppm by centrifugation at $5,000 \times g$ for $10 \mathrm{~min}$ at $4^{\circ} \mathrm{C}$ to remove residual chlorine and the resulting concentrated cell pellets were prepared for TEM by previously described methods (Capita et al., 2014). Pellets were fixed using $1 / 2$ strength Karnovsky fixative in $0.1 \mathrm{M}$ sodium cacodylate buffer ( $\mathrm{pH} 7.2)$ overnight at $4^{\circ} \mathrm{C}$. Fixed cells were washed in buffer, post fixed in $2 \%$ buffered osmium tetroxide, dehydrated through a graded ethanol series, and embedded in Spurr's resin. Ultra-thin sections were cut using a Riecher Jung Ultracut microtome, collected on copper grids and stained with uranyl acetate and lead citrate and viewed on a JEOL JSM-1230 transmission electron microscope (Jeol USA, Peabody, MA, United States) at $80 \mathrm{kv}$. For the TEM analysis, four different random areas were selected to take images for each sample. Cells were classified into normal (short rods) and stress adapted (elongated rods) based on the standard length on the similar magnification scale.

\section{Statistical Analysis}

The homologous stress adaptation assays (MIC and MBC determination to chlorine) were repeated three times. While evaluating for heterologous stress adaptation, antibiotic disk diffusion assays were repeated three times and antibiotic MIC dilution assays were repeated two times. All experimental data were analyzed using a $2 \times 3$ factorial arrangement (chlorine adapted and non-adapted treatments versus three stress periods) in a randomized complete block design with replication considered as block using SAS v. 9.4 (SAS Institute, Cary, NC, United States; Steel and Torrie, 1980). The means were separated using Fisher Protected Least Significance difference. The treatments and controls were determined to be significant when $P \leq 0.05$.

\section{RESULTS}

\section{Viable Cell Count}

Viable cell counts, and growth turbidity $\left(\mathrm{OD}_{600}\right)$ were measured to investigate effect of sublethal concentrations of chlorine exposure to L. monocytogenes strains on growth phase. Results showed that sublethal concentrations of chlorine did not significantly change in growth rate of $L$. monocytogenes strains at $37^{\circ} \mathrm{C}$. Both non-adapted control cells and chlorine adapted cells of L. monocytogenes reached the stationary phase during their overnight incubation periods prior to testing for homologous and heterologous adaptation.

TABLE 2 | List of antibiotics used in this study.

\begin{tabular}{|c|c|c|c|c|}
\hline No. & Antibiotic & Susceptibility range $(\mu \mathrm{g} / \mathrm{ml})$ & Solvent & Diluent \\
\hline$(1)$ & Ampicillin & $0.0078-1$ & Water & $\mathrm{MHB}$ \\
\hline$(2)$ & Amoxicillin & $0.0075-0.48$ & Water & $\mathrm{MHB}$ \\
\hline (3) & Ceftriaxone & $2-128$ & Water & $\mathrm{MHB}$ \\
\hline (4) & Vancomycin & $0.5-32$ & Water & $\mathrm{MHB}$ \\
\hline$(5)$ & Tetracycline & $0.03-2$ & Ethanol (70\%) & $\mathrm{MHB}$ \\
\hline (6) & Gentamicin & $0.062-4$ & Water & $\mathrm{MHB}$ \\
\hline$(7)$ & Streptomycin & $4-256$ & Water & $\mathrm{MHB}$ \\
\hline (8) & Ciprofloxacin & $0.0075-0.48$ & Water & $\mathrm{MHB}$ \\
\hline
\end{tabular}


TABLE 3 | Minimum inhibitory concentrations (MICs) and minimum bactericidal concentrations (MBCs) of chlorine (ppm) for five L. monocytogenes strains adapted to sublethal concentrations of chlorine versus control.

\begin{tabular}{|c|c|c|c|c|c|c|}
\hline \multicolumn{2}{|c|}{ Chlorine tolerance } & \multicolumn{5}{|c|}{ L. monocytogenes strains } \\
\hline & & Scott A & V7 & FSL-N1-227 & FSL-F6-154 & ATCC 19116 \\
\hline \multirow[t]{2}{*}{ MIC (ppm) } & Control & $500 \pm 0$ & $500 \pm 0$ & $500 \pm 0$ & $500 \pm 0$ & $500 \pm 0$ \\
\hline & Adapted & $600 \pm 0$ & $600 \pm 0$ & $600 \pm 0$ & $600 \pm 0$ & $500 \pm 0$ \\
\hline \multirow[t]{2}{*}{ MBC (ppm) } & Control & $600 \pm 0$ & $600 \pm 0$ & $600 \pm 0$ & $600 \pm 0$ & $600 \pm 0$ \\
\hline & Adapted & $700 \pm 0$ & $700 \pm 0$ & $700 \pm 0$ & $700 \pm 0$ & $600 \pm 0$ \\
\hline
\end{tabular}

All assays repeated three times.

TABLE 4 | Average zones of inhibition $(\mathrm{mm})$ by antibiotic disk-diffusion tests for five $L$. monocytogenes strains after chlorine induced oxidative stress adaptation (A) over three different stress levels (1/2 MIC for 1 day, 1/2-2/3 MIC over 5 days and 1/2-3/4 MIC over 7 days) versus control (C) cells.

\begin{tabular}{|c|c|c|c|c|c|c|c|c|c|c|}
\hline \multirow[t]{3}{*}{ Antibiotics $^{a}$} & \multicolumn{10}{|c|}{ L. monocytogenes strains } \\
\hline & \multicolumn{2}{|c|}{ Scott A } & \multicolumn{2}{|c|}{ v7 } & \multicolumn{2}{|c|}{ FSL-N1- 227} & \multicolumn{2}{|c|}{ FSL-F6-154 } & \multicolumn{2}{|c|}{ ATCC-19116 } \\
\hline & C & A & C & A & C & A & C & A & C & A \\
\hline AMP & $32 \pm 0.3$ & $31 \pm 0.3^{*}$ & $34 \pm 0.3$ & $31 \pm 0.3^{*}$ & $30 \pm 0.02$ & $29 \pm 0.02$ & $32 \pm 0.2$ & $30 \pm 0.2^{*}$ & $32 \pm 0.3$ & $32 \pm 0.3$ \\
\hline STR & $20 \pm 0.3$ & $18 \pm 0.3^{*}$ & $19 \pm 0.4$ & $18 \pm 0.4^{*}$ & $19 \pm 0.2$ & $17 \pm 0.2^{*}$ & $20 \pm 0.3$ & $18 \pm 0.3^{*}$ & $20 \pm 0.2$ & $18 \pm 0.2^{*}$ \\
\hline GEN & $22 \pm 0.3$ & $22 \pm 0.3$ & $22 \pm 0.2$ & $22 \pm 0.2$ & $22 \pm 0.3$ & $21 \pm 0.3$ & $22 \pm 0.4$ & $21 \pm 0.4$ & $23 \pm 0.4$ & $23 \pm 0.4$ \\
\hline AMC & $34 \pm 0.1$ & $34 \pm 0.1$ & $34 \pm 0.5$ & $33 \pm 0.5$ & $34 \pm 0.3$ & $33 \pm 0.3^{*}$ & $34 \pm 0.2$ & $30 \pm 0.2^{*}$ & $34 \pm 0.2$ & $32 \pm 0.2^{*}$ \\
\hline NA & $0^{b}$ & $0^{b}$ & $0^{\mathrm{b}}$ & $0^{\mathrm{b}}$ & $0^{b}$ & $0^{b}$ & $0^{\mathrm{b}}$ & $0^{b}$ & $\mathrm{O}^{\mathrm{b}}$ & $0^{b}$ \\
\hline SXT & $36 \pm 0.2$ & $35 \pm 0.2^{*}$ & $34 \pm 0.3$ & $34 \pm 0.3$ & $35 \pm 0.4$ & $33 \pm 0.4$ & $35 \pm 0.3$ & $32 \pm 0.3^{*}$ & $34 \pm 0.3$ & $31 \pm 0.3^{*}$ \\
\hline VAN & $22 \pm 0.3$ & $21 \pm 0.3^{*}$ & $22 \pm 0.3$ & $22 \pm 0.3$ & $22 \pm 0.3$ & $21 \pm 0.3$ & $22 \pm 1.0$ & $21 \pm 1.0$ & $23 \pm 0.2$ & $22 \pm 0.2^{*}$ \\
\hline CIP & $21 \pm 1.0$ & $20 \pm 1.0$ & $22 \pm 0.2$ & $23 \pm 0.2$ & $22 \pm 0.3$ & $22 \pm 0.3$ & $22 \pm 0.4$ & $21 \pm 0.4$ & $22 \pm 1.0$ & $21 \pm 1.0^{*}$ \\
\hline $\mathrm{RIF}$ & $24 \pm 0.3$ & $25 \pm 0.3^{*}$ & $25 \pm 1.0$ & $24 \pm 1.0$ & $25 \pm 0.2$ & $24 \pm 0.2^{*}$ & $24 \pm 0.3$ & $25 \pm 0.29$ & $25 \pm 0.3$ & $24 \pm 0.3$ \\
\hline CTX & $0^{b}$ & $0^{b}$ & $14 \pm 0.3$ & $13 \pm 0.3$ & $0^{b}$ & $0^{b}$ & $14 \pm 0.3$ & $13 \pm 0.3$ & $14 \pm 0.2$ & $12 \pm 0.2^{*}$ \\
\hline
\end{tabular}

All assays were repeated three times.

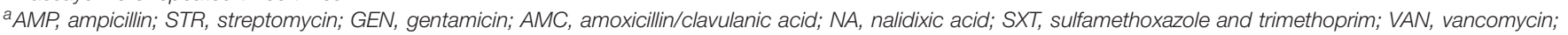

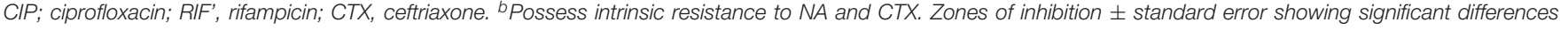
between control and adapted cells are highlighted in bold. *Indicate $p<0.05$.

\section{Homologous Stress Adaptation (Changes in Chlorine Tolerance)}

Homologous stress adaptation of L. monocytogenes to chlorine was determined by measuring the changes in MIC and MBC for sodium hypochlorite. The MIC of sodium hypochlorite for control L. monocytogenes was $500 \mathrm{ppm}$ for all five strains (Scott A, V7, N1-2227, F6-154, and ATCC 19116) studied. After exposure to the sublethal oxidative stress induced by chlorine, the average MIC of sodium hypochlorite was slightly increased to $600 \mathrm{ppm}$ for cells at all three sublethal stress levels, i.e., 250, 330, and 375 ppm in four strains (Scott A, V7, N1-227, and F6-154). However, there was no change in MIC to sodium hypochlorite for the reference strain ATCC 19916 under these experimental conditions.

The MBC of sodium hypochlorite for L. monocytogenes showed similar trends of adaptive tolerance to sodium hypochlorite, where average $\mathrm{MBC}$ was increased to $700 \mathrm{ppm}$ for strains Scott A, V7, N1-227, F6-154 from the initial 600 ppm for cells at all sublethal stress levels (250,330, and $375 \mathrm{ppm}$ ). However, no change in MBC was observed for the reference strain ATCC 19116 (Table 3).

\section{Heterologous Stress Adaptation (Changes in Antibiotic Susceptibility)}

Antibiotic susceptibility of five strains of $L$. monocytogenes was measured by the Kirby-Bauer disk diffusion assay and MIC dilution assay as per CLSI (2016) guidelines. The antibiotic susceptibility patterns of the oxidative stress adapted and control cells from both the disk diffusion assay and MIC dilution method are shown in Tables 4, 5. L. monocytogenes strains were screened for susceptibility to different classes of antibiotics before and after gradual exposure to the increasing concentrations of sodium hypochlorite. All five strains tested were found to have intrinsic resistance to nalidixic acid while 2 of the five strains tested (Scott A and N1-227) have intrinsic resistance to ceftriaxone (a third-generation cephalosporin). The average zone of inhibition was slightly decreased by $0.5-$ $2.2 \mathrm{~mm}$ compared to controls for all 11 antibiotics tested. Interestingly, the disk diffusion assay showed that all fivestrains studied in the present study develop significant tolerance for streptomycin $(p<0.05)$. Significant antibiotic tolerance development was also observed for antibiotics such as ampicillin, amoxicillin, sulfamethoxazole and trimethoprim, ciprofloxacin, 
TABLE 5 | Average minimum inhibitory concentrations (MICs) of antibiotics for five L. monocytogenes strains after chlorine induced oxidative stress adaptation (A) over three different stress levels (1/2 MIC for 1 day, 1/2-2/3 MIC over 5 days and 1/2-3/4 MIC over 7 days) versus control (C).

\begin{tabular}{|c|c|c|c|c|c|c|c|c|c|c|}
\hline \multirow[t]{2}{*}{ Antibiotics $^{a}$} & \multicolumn{10}{|c|}{ L. monocytogenes strains } \\
\hline & \multicolumn{2}{|c|}{ Scott A } & \multicolumn{2}{|c|}{ v7 } & \multicolumn{2}{|c|}{ FSL-N1- 227} & \multicolumn{2}{|c|}{ FSL-F6-154 } & \multicolumn{2}{|c|}{ ATCC-19116 } \\
\hline AMP & $0.3 \pm 0.04$ & $0.3 \pm 0.04$ & $0.08 \pm 0.01$ & $0.2 \pm 0.01^{*}$ & $0.5 \pm 0.09$ & $0.6 \pm 0.09$ & $0.25 \pm 0.0$ & $0.25 \pm 0.0$ & $0.3 \pm 0.06$ & $0.4 \pm 0.06$ \\
\hline TET & $0.3 \pm 0.02$ & $0.5 \pm 0.02^{*}$ & $0.3 \pm 0.04$ & $0.5 \pm 0.04^{*}$ & $1.0 \pm 0.2$ & $0.9 \pm 0.2$ & $1.12 \pm 0.0$ & $1.12 \pm 0.0$ & $0.5 \pm 0.3$ & $0.6 \pm 0.26$ \\
\hline AMX & $0.1 \pm 0.02$ & $0.14 \pm 0.02$ & $0.12 \pm 0.1$ & $0.15 \pm 0.01$ & $0.4 \pm 0.0$ & $0.4 \pm 0.0$ & $0.2 \pm 0.03$ & $0.3 \pm 0.03$ & $0.2 \pm 0.0$ & $0.2 \pm 0.0$ \\
\hline VAN & $0.5 \pm 0.0$ & $0.5 \pm 0.0$ & $0.5 \pm 0.0$ & $0.5 \pm 0.0$ & $0.5 \pm 0.0$ & $0.5 \pm 0.0$ & $0.5 \pm 0.0$ & $0.5 \pm 0.0$ & $0.5 \pm 0.0$ & $0.5 \pm 0.0$ \\
\hline CIP & $0.3 \pm 0.0$ & $0.3 \pm 0.0$ & $0.3 \pm 0.0$ & $0.3 \pm 0.0$ & $0.3 \pm 0.0$ & $0.5 \pm 0.0^{*}$ & $0.4 \pm 0.0$ & $0.5 \pm 0.0$ & $0.5 \pm 0.0$ & $0.5 \pm 0.0$ \\
\hline CTX & $17 \pm 3.0$ & $29 \pm 3.0^{*}$ & $7.3 \pm 0.59$ & $7 \pm 0.59$ & $19 \pm 1.8$ & $27 \pm 1.8^{*}$ & $6.6 \pm 0.0$ & $8 \pm 0.0$ & $8 \pm 0.0$ & $32 \pm 0.0$ \\
\hline
\end{tabular}

All assays repeated two times.

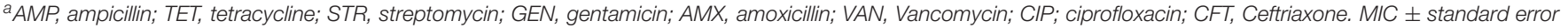
showing significant differences between control and adapted cells are highlighted in bold. *Indicate $p<0.05$.

rifampicin, and ceftriaxone after sublethal chlorine exposure to L. monocytogenes by disk diffusion assay. Results showed that the effect of sublethal chlorine exposure on L. monocytogenes has significantly decreased its zone of inhibition for few of antibiotics, however, it did not influence antibiotic susceptibility zone.

Similarly, development of antibiotic tolerance was measured after sublethal chlorine exposure to L. monocytogenes with double dilution MIC assay. The assay showed that significant antibiotic tolerance was developed for ampicillin (one strain), tetracycline (two strains), streptomycin (one strain), and ceftriaxone (three strains). A major change in MIC was observed for the reference strain ATCC 19116 which exhibited a fourfold increase in MIC to ceftriaxone after sublethal chlorine adaptation (Table 5). A minor but significant change in antibiotic susceptibility range for ceftriaxone was also observed in two intrinsic resistant strains, Scott A and N1-227, in chlorine oxidative stress adapted cells of L. monocytogenes. The decrease in zone of inhibition and increase in MIC for antibiotics after sublethal chlorine exposure could be related with phenotypic antibiotic tolerance development in L. monocytogenes.

\section{Changes in Ultrastructure of L. monocytogenes in the Presence of Sodium Hypochlorite}

Sublethal chlorine induced oxidative stress caused significant and consistent morphological changes in L. monocytogenes strains Scott A, V7 and N1-227 which included: (1) changes in cell length, (2) changes in cell wall thickness, (3) changes in cell membrane shape; and (4) cytoplasmic changes. Sublethal chlorine adapted L. monocytogenes exhibited a consistent elongation of cells, presence of multiple chromosomes and membrane bleb formations which may indicate transient inhibition of cell division (Figures 1, 2 and Supplementary Figure S1).

Along with the elongated cells, outer membrane bleb formation and wavy cell envelop structures were frequently observed in chlorine stress adapted cells of

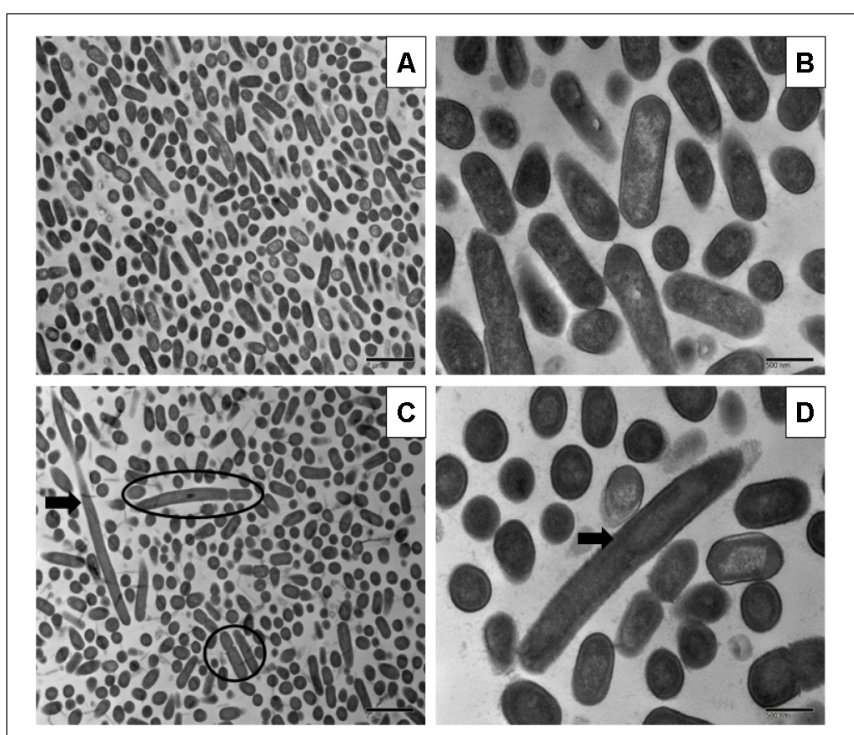

FIGURE 1 | Transmission electron micrographs of Listeria monocytogenes Scott A non-adapted (A,B) and oxidative stress adapted cells (C,D) after gradually exposing to $375 \mathrm{ppm}$ ( $3 / 4 \mathrm{MIC}$ ) from $250 \mathrm{ppm}$ (1/2 MIC) of chlorine over 7 days. Micrographs represent planktonic cells: $(\mathbf{A}, \mathbf{B})$ control cells at different magnifications; (C,D) elongated cells and bud formation, indicated by arrow and multi-chromosome formation indicated by red circle in chlorine adapted cells at different magnifications.

L. monocytogenes which may be associated with the activation of a bacterial phenotypic response to sublethal oxidative stress.

\section{DISCUSSION}

The objective of this study was to evaluate the influence of sublethal concentrations of sodium hypochlorite on homologous and heterologous stress adaptation in L. monocytogenes in laboratory condition simulating food processing environment. 


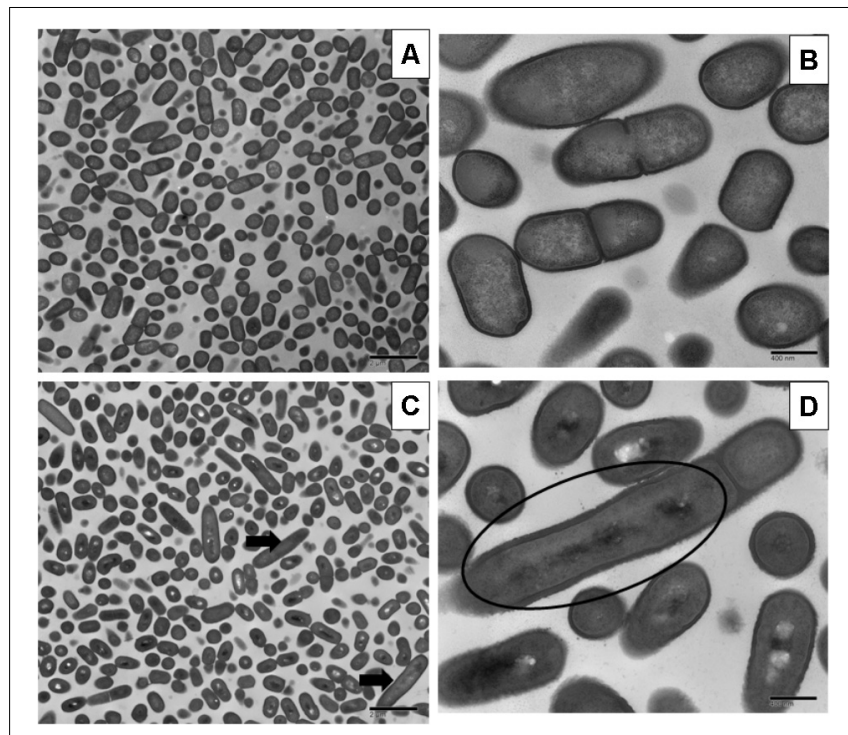

FIGURE 2 | Transmission electron micrographs of $L$. monocytogenes V7 non-adapted $\mathbf{( A , C )}$ and oxidative stress adapted cells (B,D) gradually exposing to 375 ppm (3/4 MIC) from 250 ppm (1/2 MIC) of chlorine over 7 days. Micrographs represent planktonic cells: $(\mathbf{A}, \mathbf{B})$ control cells at different magnifications; (C,D) elongated cells and bud formation indicated by arrow, and multi-chromosome formation and inhibition of cell division indicated by red circle in chlorine adapted cells at different magnifications.

Various sanitizers and disinfectants are routinely used at $>1,000$ times concentrations than that of their MIC for killing foodborne pathogens in the food-processing plants. The high concentrations of sanitizers and disinfectants interacts with multiple mechanisms in bacterial cells, such as degeneration of proteins, and lipids, as well as DNA degradation (Gray et al., 2014). In food processing environments, bacterial cells are frequently exposed to lower or sublethal concentrations of biocides because of dilution of biocide by water abundance and presence of organic matter. Similar conditions of sublethal exposure are also occurred in wastewater plants, hospitals, or in processing plant effluents. Recent findings show that the sublethal concentrations of biocides interact with a single central bacterial response and such gradual exposure of sublethal concentrations can co-select resistance to biocides as well as to antibiotics (Capita et al., 2014; Gray et al., 2014; Wales and Davies, 2015; Webber et al., 2015). Therefore, it is important to understand the role of sublethal concentrations at which biocides can select or co-select for antibiotic resistance in whole or subpopulations of bacterial cells.

Listeria monocytogenes strains Scott A, V7, N1-227, and F6-154 exhibited homologous stress adaptation in TSB with a 100-ppm increase in chlorine tolerance as evidenced by increase in MIC and MBC. In other studies, Kastbjerg and Gram (2012) exposed L. monocytogenes EGD to the disinfectants hypochlorite and Incimaxx DES (peracetic acid and hydrogen peroxide) for several hundred generations (300-420 bacterial generations) and found no changes in the MIC, whereas exposure to Triquart SUPER (quaternary ammonium compounds) caused a two-fourfold increase in MIC. However, in the present study MIC was determined at a close range of 500, 600, 700, and $800 \mathrm{ppm}$ chlorine concentrations after 1,5 , or 7 serial transfers which showed that development of homologous stress adaptation after serial transfer in presence of sublethal chlorine concentrations. Chlorine reacts with organic compounds in media (TSB) and forms a reactive chlorine species (RCS) such as chloramines. The RCS then reacts with sulfur containing compounds such as amino acids (cysteine, methionine or glutathione), and primary or secondary amines, nucleotides and lipids. While the higher concentration of RCS damages the bacterial DNA, bacteria can generate adaptations when exposed to a lower or sublethal concentration. Bacteria quickly respond to RCS by the high expression of enzymes, such as catalases, peroxidases, and methionine sulfoxide reductase. In response to damaged DNA caused by RCS, bacteria upregulate homologous recombination, repair and mutagenic polymerases (Gray et al., 2014).

Antibiotic susceptibility is measured by disk diffusion, $E$-test and broth microdilution assay. The broth microdilution method is the primarily standard reference method for quantifying antibiotic susceptibility/resistance responses in clinical and research labs (CLSI, 2016). This method is a technically simple, fast, and low-cost method compared to E-test (Luber et al., 2003). In the present study, Kirby-Bauer disk diffusion and broth microdilution assay was used for analysis of antibiotic susceptibility. For clinical purpose, drug dosage is a function of MIC, half-life and distribution volume of antibiotic. MIC is an important factor in calculation of antibiotic dose and increase in MIC will decrease pharmacodynamics index and result in unlikely clinical response (MacGowan, 2008). In present study, heterologous stress adaptation results showed that L. monocytogenes developed minor but statistically significant increase in MICs for commonly used antibiotics which may impact on increase of antibiotic dosage and also causes antibiotic resistance.

The antibiotic resistance against third generation cephalosporins in L. monocytogenes was reported from different countries. Ceftriaxone resistance in human listeriosis cases were reported from Vietnam (Chau et al., 2010), Bangladesh (Ahmed et al., 2015), and Turkey (Kose and Yakupogullari, 2015). Strains of a bacterial species will have varying MICs where sensitive strains will have relatively low MICs, and resistant strains will have relatively high MICs (Turnidge and Paterson, 2007). Interestingly, ceftriaxone intrinsic resistant was found in strains Scott A and N1-227, while the reference strain ATCC 19116 showed fourfold adaptive resistance after sublethal chlorine exposure. Al-Nabulsi et al. (2015) demonstrated that antibiotic resistance in L. monocytogenes was increased after exposing it to $6 \%$ or $12 \% \mathrm{NaCl}$, reducing the $\mathrm{pH}$ to 5 , and decreasing the temperature to $10^{\circ} \mathrm{C}$. L. monocytogenes isolates from meat and dairy have also been found to be more resistant than its reference ATCC 19116 strain.

Stress adapted bacterial cells change their morphology and led to development of persisters, which may help in their ability to 
tolerate higher concentrations of antibiotics and antimicrobials (Levin and Rozen, 2006; Dawson et al., 2011). The development of persisters is observed under different conditions such as intracellular stress response (Dörr et al., 2009), oxidative stress response (Vega et al., 2012) and stringent response (Amato and Brynildsen, 2014). At sublethal concentrations, chlorine and RCS species can induce the SOS response, a state of temporary stop in bacterial cell division in bacteria and change to a long rod shape with multi-chromosomes containing long filaments. Bos et al. (2014) investigated the role of bud formation in antibiotic resistance propagation of Escherichia coli after sublethal ciprofloxacin exposure. In the present study, sublethal chlorine induced oxidative stress consistently induced persisters or multi chromosomal long rods in all three strains studied using TEM, which may aid in the increase of antibiotic tolerance. Our present findings of L. monocytogenes cell elongation and cell wall roughness as a bacterial response in stress adapted cells is in agreement with previous investigations (To et al., 2002). These results suggest a major role of outer member modulations in L. monocytogenes adaptive responses to antimicrobials and antibiotics (Ernst et al., 2001; Sallum and Chen, 2008). Similar to previous findings (Gray et al., 2014), we have also observed that L. monocytogenes cells also formed multi-chromosome filaments with buds in response to chlorine stress by electron microscopy studies.

\section{CONCLUSION}

Our results show that the exposure to sublethal concentrations of chlorine could potentially have impact on the cross-responses of L. monocytogenes to commonly used antibiotics, enabling microorganisms to adapt to adverse environmental conditions and enhance antibiotic resistance. The changes in cell wall and membrane integrity resulting from the elongation of cells may contribute to possible routes of $L$. monocytogenes response for

\section{REFERENCES}

Ahmed, D., Sadique, T., Sami, A. B., Abdullah, A., Nahid, M. A., Hossain, A., et al. (2015). Listeria monocytogenes infection in a 56-year-old female cancer patient: a case report. JMM Case Rep. 2, 2-5. doi: 10.1099/jmmcr.0.000076

Allerberger, F., and Wagner, M. (2010). Listeriosis: a resurgent foodborne infection. Clin. Microbiol. Infect. 16, 16-23. doi: 10.1111/j.1469-0691.2009.03109.x

Al-Nabulsi, A. A., Osaili, T. M., Shaker, R. R., Olaimat, A. N., Jaradat, Z. W., Zain Elabedeen, N. A., et al. (2015). Effects of osmotic pressure, acid, or cold stresses on antibiotic susceptibility of Listeria monocytogenes. Food Microbiol. 46, 154-160. doi: 10.1016/j.fm.2014.07.015

Amato, S. M., and Brynildsen, M. P. (2014). Nutrient transitions are a source of persisters in Escherichia coli biofilms. PLoS One 9:e93110. doi: 10.1371/journal. pone.0093110

Begley, M., Sleator, R. D., Gahan, C. G., and Hill, C. (2005). Contribution of three bile-associated loci, bsh, pva, and btlB, to gastrointestinal persistence and bile tolerance of Listeria monocytogenes. Infect. Immun. 73, 894-904. doi: 10.1128/ IAI.73.2.894-904.2005

Bos, J., Zhang, Q., Vyawahare, S., Rogers, E., Rosenberg, S. M., and Austin, R. H. (2014). Emergence of antibiotic resistance from multinucleated bacterial minor but significant increase in tolerance to chlorine and selective antibiotics.

\section{AUTHOR CONTRIBUTIONS}

The research was designed and led by RN from FSNHP and by $\mathrm{CS}$ and $\mathrm{AK}$ from POSC and was completed by MB while working for his Masters thesis research.

\section{FUNDING}

This material was based upon the work that was supported by the National Institute of Food and Agriculture, United States Department of Agriculture for the project MIS-401180 under award number 2016-69003-24600. Also, funded in part by Food Safety Initiative award to RN and CS from the Mississippi Agricultural and Forestry Experiment Station under project MIS-401190 with grant number USDA-ARS SCA No. 58-64022729. We thank Ms. Amanda Lawrence, Outreach Coordinator; Institute for Imaging \& Analytical Technologies at Mississippi State University, United States for providing support for TEM analysis.

\section{SUPPLEMENTARY MATERIAL}

The Supplementary Material for this article can be found online at: https://www.frontiersin.org/articles/10.3389/fmicb. 2018.02050/full\#supplementary-material

FIGURE S1 | Transmission electron micrographs of Listeria monocytogenes N1-227 non-adapted $(\mathbf{A}, \mathbf{B})$ and oxidative stress adapted cells $\mathbf{( C - F )}$ gradually exposing to 375 ppm (3/4 MIC) from 250 ppm (1/2 MIC) of chlorine over 7 days. Micrographs represent planktonic cells: $(\mathbf{A}, \mathbf{B})$ control cells at different magnifications; (C-F) elongated cells and bud formation, indicated by arrow and multi-chromosome formation indicated by black circle in chlorine adapted cells at different magnifications.

filaments. Proc. Natl. Acad. Sci. U.S.A. 12, 178-183. doi: 10.1073/pnas. 1420702111

Capita, R., Riesco-Peláez, F., Alonso-Hernando, A., and Alonso-Calleja, C. (2014). Exposure of Escherichia coli ATCC 12806 to sublethal concentrations of foodgrade biocides influences its ability to form biofilm, resistance to antimicrobials, and ultrastructure. Appl. Environ. Microbiol. 80, 1268-1280. doi: 10.1128/AEM. 02283-13

Capozzi, V., Fiocco, D., Amodio, M. L., Gallone, A., and Spano, G. (2009). Bacterial stressors in minimally processed food. Int. J. Mol. Sci. 10, 3076-3105. doi: 10.3390/ijms10073076

Carpentier, B., and Cerf, O. (2011). Review - persistence of Listeria monocytogenes in food industry equipment and premises. Int. J. Food Microbiol. 145, 1-8. doi: 10.1016/j.ijfoodmicro.2011.01.005

CDC (2012). National Enteric Disease Surveillance: The Listeria Initiative. Available at: https://www.cdc.gov/listeria/pdf/ListeriaInitiativeOverview_508. pdf [Accessed July 16, 2018].

Chau, T. T. H., Campbell, J. I., Schultsz, C., van Vinh Chau, N., Diep, T. S., Baker, S., et al. (2010). Three adult cases of Listeria monocytogenes meningitis in Vietnam. PLoS Med. 7:e1000306. doi: 10.1371/journal.pmed.10 00306 
CLSI (2016). M45-A2. Methods for Antimicrobial Dilution and Disk Susceptibility Testing of Infrequently Isolated or Fastidious Bacteria, 3rd Edn. Wayne, PA: Clinical and Laboratory Standards Institute.

Dawson, C. C., Intapa, C., and Jabra-Rizk, M. A. (2011). "Persisters": survival at the cellular level. PLoS Pathog. 7:e1002121. doi: 10.1371/journal.ppat.1002121

Dörr, T., Lewis, K., and Vulić, M. (2009). SOS response induces persistence to fluoroquinolones in Escherichia coli. PLoS Genet. 5:e1000760. doi: 10.1371/ journal.pgen.1000760

Ernst, R. K., Guina, T., and Miller, S. I. (2001). Salmonella typhimurium outer membrane remodeling: role in resistance to host innate immunity. Microbes Infect. 3, 1327-1334. doi: 10.1016/S1286-4579(01)01494-0

Fair, R. J., and Tor, Y. (2014). "Antibiotics and bacterial resistance in the 21st century," in Perspectives in Medicinal Chemistry, ed. B. Testa (Hoboken, NJ: Wiley), 25-64.

Forbes, S., Dobson, C. B., Humphreys, G. J., and McBain, A. J. (2014). Transient and sustained bacterial adaptation following repeated sublethal exposure to microbicides and a novel human antimicrobial peptide. Antimicrob. Agents Chemother. 58, 5809-5817. doi: 10.1128/AAC.03364-14

Gadea, R., Fernández Fuentes, M. Á., Pérez Pulido, R., Gálvez, A., and Ortega, E. (2017). Effects of exposure to quaternary-ammonium-based biocides on antimicrobial susceptibility and tolerance to physical stresses in bacteria from organic foods. Food Microbiol. 63, 58-71. doi: 10.1016/j.fm.2016. 10.037

Gao, H., and Liu, C. (2014). Biochemical and morphological alteration of Listeria monocytogenes under environmental stress caused by chloramine-T and sodium hypochlorite. Food Control 46, 455-461. doi: 10.1016/j.foodcont.2014. 05.016

Gray, M. J., Wholey, W., and Jakob, U. (2014). Bacterial responses to reactive chlorine species NIH Public. Access. Annu. Rev. Microbiol. 67, 141-160. doi: 10.1146/annurev-micro-102912-142520

Henshaw, D. L., and O'Carroll, M. J. (2009). Scientific Committee on Emerging and Newly Identified Health Risks (SCENIHR). Brussels: European Commission.

Holah, J. T., Taylor, J. H., Dawson, D. J., and Hall, K. E. (2002). Biocide use in the food industry and the disinfectant resistance of persistent strains of Listeria monocytogenes and Escherichia coli. Symp. Ser. Soc. Appl. Microbiol. 92, 111S-120S. doi: 10.1046/j.1365-2672.92.5s1.18.x

Kastbjerg, V. G., and Gram, L. (2012). Industrial disinfectants do not select for resistance in Listeria monocytogenes following long term exposure. Int. J. Food Microbiol. 160, 11-15. doi: 10.1016/j.ijfoodmicro.2012.09.009

Kose, A., and Yakupogullari, Y. (2015). A rapidly fatal sepsis caused by Listeria monocytogenes type- $4 \mathrm{~b}$ in a patient with chronic renal failure. Jundishapur $J$. Microbiol. 8:e19980. doi: 10.5812/jjm.19980

Levin, B. R., and Rozen, D. E. (2006). Non-inherited antibiotic resistance. Nat. Rev. Microbiol. 4, 556-562. doi: 10.1038/nrmicro1445

Luber, P., Bartelt, E., Genschow, E., Wagner, J., and Hahn, H. (2003). Comparison of broth microdilution, E test, and agar dilution methods for antibiotic susceptibility testing of Campylobacter jejuni and Campylobacter coli. J. Clin. Microbiol. 41, 1062-1068. doi: 10.1128/jcm.41.3.1062-1068. 2003

MacGowan, A. P. (2008). Clinical implications of antimicrobial resistance for therapy. J. Antimicrob. Chemother. 62, 105-114. doi: 10.1093/jac/ dkn357

Martínez-Suárez, J. V., Ortiz, S., and López-Alonso, V. (2016). Potential impact of the resistance to quaternary ammonium disinfectants on the persistence of Listeria monocytogenes in food processing environments. Front. Microbiol. 7:638. doi: 10.3389/fmicb.2016.00638
McMahon, M. A. S., Xu, J., Moore, J. E., Blair, I. S., and McDowell, D. A. (2007). Environmental stress and antibiotic resistance in food-related pathogens. Appl. Environ. Microbiol. 73, 211-217. doi: 10.1128/AEM.00578-06

Mead, P. S., Slutsker, L., Dietz, V., McCaig, L. F., Bresee, J. S., Shapiro, C., et al. (1999). Food-related illness and death in the United States. Emerg. Infect. Dis. 5, 607-625. doi: 10.3201/eid0505.990502

Romero, J. L., Grande Burgos, M. J., Pérez-Pulido, R., Gálvez, A., and Lucas, R. (2017). Resistance to antibiotics, biocides, preservatives and metals in bacteria isolated from seafoods: co-selection of strains resistant or tolerant to different classes of compounds. Front. Microbiol. 8:1650. doi: 10.3389/fmicb.2017.01650

Sallum, U. W., and Chen, T. T. (2008). Inducible resistance of fish bacterial pathogens to the antimicrobial peptide cecropin B. Antimicrob. Agents Chemother. 52, 3006-3012. doi: 10.1128/AAC.00023-08

Scallan, E., Hoekstra, R. M., Angulo, F. J., Tauxe, R. V., Widdowson, M. A., Roy, S. L., et al. (2011). Foodborne illness acquired in the United States-major pathogens. Emerg. Infect. Dis. 17, 7-15. doi: 10.3201/eid1701.P11101

Seier-Petersen, M. A. (2013). "Development of bacterial resistance to biocides and antimicrobial agents as a consequence of biocide usage," in Division Epidemiology and Microbial Genomics National Food Institute, (Kongens Lyngby: Technical. University of Denmark).

Steel, R. G. D., and Torrie, J. H. (1980). Principles and Procedures of Statistics. A Biometrical Approach, 2nd Edn. New York, NY: McGraw-Hill, 20-90.

To, M. S., Favrin, S., Romanova, N., and Griffiths, M. W. (2002). Postadaptational resistance to benzalkonium chloride and subsequent physicochemical modifications of Listeria monocytogenes. Appl. Environ. Microbiol. 68, 5258-5264. doi: 10.1128/AEM.68.11.5258-5264.2002

Turnidge, J., and Paterson, D. L. (2007). Setting and revising antibacterial susceptibility breakpoints. Clin. Microbiol. Rev. 20, 391-408. doi: 10.1128/cmr. 00047-06

Vega, N. M., Allison, K. R., Khalil, A. S., and Collins, J. J. (2012). Signalingmediated bacterial persister formation. Nat. Chem. Biol. 8, 431-433. doi: 10. 1038/nchembio.915

Wales, A., and Davies, R. (2015). Co-Selection of resistance to antibiotics, biocides and heavy metals, and its relevance to foodborne pathogens. Antibiotics 4, 567-604. doi: 10.3390/antibiotics4040567

Webber, M. A., Whitehead, R. N., Mount, M., Loman, N. J., Pallen, M. J., and Piddock, L. J. V. (2015). Parallel evolutionary pathways to antibiotic resistance selected by biocide exposure. J. Antimicrob. Chemother. 70, 2241-2248. doi: $10.1093 / \mathrm{jac} / \mathrm{dkv} 109$

Wiuff, C., Zappala, R. M., Regoes, R. R., Garner, K. N., and Levin, B. R. (2005). Phenotypic tolerance: antibiotic enrichment of noninherited resistance in bacterial populations phenotypic tolerance: antibiotic enrichment of noninherited resistance in bacterial populations. Antimicrob. Agents Chemother. 49, 1483-1494. doi: 10.1128/AAC.49.4.1483

Conflict of Interest Statement: The authors declare that the research was conducted in the absence of any commercial or financial relationships that could be construed as a potential conflict of interest.

Copyright (c) 2018 Bansal, Nannapaneni, Sharma and Kiess. This is an open-access article distributed under the terms of the Creative Commons Attribution License (CC BY). The use, distribution or reproduction in other forums is permitted, provided the original author(s) and the copyright owner(s) are credited and that the original publication in this journal is cited, in accordance with accepted academic practice. No use, distribution or reproduction is permitted which does not comply with these terms. 